\title{
Relações Federativas no repasse de recursos à educação na Argentina: o sistema de co- participação federal de impostos
}

\author{
Federative relations financial resources in Argentinean \\ education: the system of co-participation in federal taxes
}

Karoline Jardim

\section{Resumo:}

Este artigo procura tratar da importância das relações federativas no modo como os recursos para a educação são distribuídos na Argentina. Para isso será considerado o sistema federal de co-participação de impostos, criado ainda na década de 1930 com o intuito de equilibrar as disparidades econômicas regionais por meio de arrecadação de impostos e sua posterior redistribuição entre Governo Nacional e províncias. Ao longo dos anos, porém, o que se viu foi que esse sistema funciona sob critérios de distribuição altamente questionáveis, não servindo ao seu principal objetivo de alcançar a equidade entre os entes federados. Como os recursos que são redistribuídos por esse sistema também são direcionados à educação, os problemas encontrados em seu funcionamento acabam afetando o quanto cada província aloca para seu sistema educacional.

Palavras-chave: co-participação federal de impostos; Argentina; educação; relações federativas.

\begin{abstract}
:
This article is about the importance of federal relations and how this organization influences in the way the resources are allocated to education in Argentina. It will be considered the federal system of co-participation of taxes, created in the $30 \mathrm{~s}$ in order to balance regional economic disparities by raising taxes and redistributing them among the national government and provinces. Over the years, however, what we saw is that this system works under the criteria of distribution highly questionable, not serving its primary objective of achieving equity among the provinces. As resources are reallocated by this system are also directed to education, the problems of this system can affect how much each province allocates to its educational system.
\end{abstract}

Keywords: co-participação federal de impostos; Argentina; educação; relações federativas. 
Desde 1980, mas mais especificamente na década de 1990, a descentralização dos serviços sociais teve uma importância muito grande nas políticas públicas dos países da America Latina; na área educacional, países como Argentina, Chile, Nicarágua, Brasil, Bolívia, Colômbia e México fizeram parte desta experiência.

Em 1978 houve na Argentina um processo de descentralização que transferiu as escolas primárias e pré-primárias às províncias, à municipalidade da Cidade de Buenos Aires e ao território da Terra do Fogo como parte de uma política fiscal para aliviar o gasto do Governo Nacional. Por se tratar de uma ação ocorrida no período militar, o executivo nacional impôs sua decisão às províncias, além de não terem ocorrido as correspondentes transferências para que os governos provinciais suprissem a manutenção dos serviços transferidos (NICOLINI e outros, 2001). Nesta ocasião, foram transferidas aproximadamente 6.500 escolas, 65.000 empregados públicos e 900.000 estudantes (FALLETI, 2004).

Somente a partir de 1988 a nova lei de coparticipação considerou que essa transferência significava um aumento dos gastos das províncias, culminando em um aumento da participação primária na fatia da massa co-participável de $48,5 \%$ para $56,66 \%$.

No ano de 1991 por iniciativa do Ministério da Economia, com a Lei de Transferência (Lei 24.029), houve a transferência do restante dos serviços educativos nacionais não universitários, com um amplo número de escolas secundárias repassadas às províncias e à municipalidade da Cidade de Buenos Aires e, como no primeiro caso, foi justificada por motivos fiscais.

Tal e qual ocorrido na década de 1970, a transferência dos anos 1990 também não foi acompanhada pelo aumento dos recursos que correspondessem aos gastos que as províncias teriam com os serviços transferidos; em geral as províncias aceitaram, sem grandes questionamentos, as novas responsabilidades visto que játinham vivido uma situação semelhante em 1978 (NICOLINI e outros, 2001). A partir de 1992, neste contexto, o Ministério da Educação tornou-se um ministério sem escolas.
É importante lembrar que embora estivessem previstas na Lei 24.049 transferências fixas de dinheiro da Nação às províncias, com o aumento da quantidade de alunos e mudanças nos salários dos docentes essa quantidade de dinheiro logo passou a ser insuficiente, já que essas mudanças não trouxeram atualizações nesta quantidade de dinheiro transferida. ${ }^{2}$

Com respeito à aceitação desta responsabilidade pelas províncias, Morduchowicz esclarece que "(...) em meados do ano de 1991 se aludiu à necessidade de diminuir a parcela de arrecadação de impostos co-participáveis das províncias. Diante da impossibilidade de realizar essa operação devido à resistência destas últimas, as autoridades econômicas nacionais conseguiram a via alternativa de diminuir parte de seus gastos transferindo-os às províncias." A aceitação deste esquema significou uma espécie de "ilusão monetária provincial, já que os governos provinciais conseguiram se opor à retirada de recursos co-participáveis, mas aceitaram o incremento de seus gastos. Fiscalmente, o efeito foi exatamente o mesmo" (2002, p. 50).

O processo de descentralização não ocasionou dificuldades e mudanças somente de ordem financeira; Krawczyk aponta que "(...) os problemas vinculados à prestação de educação formal deixam de ser uma preocupação nacional (...) e as autoridades educativas provinciais e os docentes perdem uma referência de qualidade pedagógica e de base salarial nacional" (2005, p. 4). Desse fato depreende-se que a iniciativa do Governo Nacional em diminuir seus gastos trouxe como consequências às províncias muito mais do que obstáculos financeiros: as perdas de referência sofridas pelos docentes e pelos governos provinciais são efeitos claros da iniciativa do Governo Nacional argentino de querer eximir-se de suas responsabilidades, tanto financeiras como políticas, no âmbito educacional. Além disso, esse processo correu

2 Embora não serão tratadas como temas desta dissertação, é importante ressaltar que esse problema ficou ainda mais grave com a Lei de Financiamento Educativo (26.075/06) e com a Lei 26.206/06, as quais prevêem maiores recursos para a educação. 
de forma um tanto anárquica, sem que houvesse as mudanças necessárias para a fusão de dois sistemas diferentes (idem).

Os aspectos positivos da descentralização ficam por conta da percepção dos docentes nacionais, que consideraram esse processo como uma forma de flexibilizar a organização um tanto burocrática do sistema educativo, uma vez que qualquer solicitação de natureza administrativa precisava ser encaminhada para o Ministério da Educação da Nação e esperar dele uma resposta à demanda provincial (KRAWCZYK, 2005).

A Lei Federal de Educação de 1993 correspondeu a um avanço do governo nacional em direção à reforma educativa no país, pois a partir dela se modificou a estrutura dos níveis do sistema educativo, se definiu as principais responsabilidades das instituições de educação e se estabeleceu os conteúdos do novo currículo.

Em termos de conteúdo, a Lei Federal expressa a vontade política de uma transformação estrutural do sistema educativo argentino a fim de atualizá-lo e adequá-lo às exigências da sociedade do fim do século. Essa lei é importante por vários fatores:

regula o funcionamento de todos os níveis do sistema, exceto o universitário;

estabelece de maneira precisa as atribuições da nação, das províncias e da cidade de Buenos Aires em matéria de governo e administração da educação;

outorga um papel importante ao Conselho Federal de Cultura e Educação como órgão de coordenação do sistema nacional de educação, ficando a seu cargo a definição das políticas;

incorpora normas relativas ao financiamento da educação do país, tentando assegurar a provisão dos fundo necessários para oferecer um serviço educativo de qualidade.

Embora em vigência a partir de 1993, as diferenças existentes entre as províncias evidenciam a autonomia de cada uma delas no que se refere à aplicação da Lei Federal: existem províncias que a aplicaram de forma completa, outras que convivem com o sistema antigo e com o novo e outras onde diretamente não se aplicou a lei. Essas situações ficarão mais evidentes no capítulo em que trataremos com mais detalhes sobre a situação da educação nas províncias.
Todos esses fatores caracterizam o sistema educativo argentino à luz do federalismo. Cada província é um lugar político diferente, com sua própria história, lógica de poder interno e sociedade.

A lógica do federalismo fiscal condiciona o federalismo educativo na medida em que permanecem situações que marcam as grandes desigualdades que afetam o financiamento dos sistemas educativos. "Isto se combina com a grande diversidade de culturas políticas locais nas províncias, que vão desde regimes dominados por caudilhos e práticas quase feudais (Formosa, La Rioja) até casos de maior participação democrática e oposição de partidos (Mendoza e Cidade de Buenos Aires)." (Rivas, A. e outros, 2004, p. 32).

O quanto se investe na educação também muda conforme a região geográfica em que se está: províncias como Santa Cruz, Terra do Fogo e Neuquén chegam a investir mais de $\$ 1.900$ por ano, por aluno da educação básica, enquanto que Corrientes e Chaco investem uma média de $\$ 850$, fato que exemplifica as disparidades educacionais do país e evidencia mais uma face das consequências advindas do sistema de coparticipação vigente na Argentina (MEZZADRA e RIVAS, 2005).

No que se refere especificamente ao financiamento, a Lei Federal estabelece em seu art. $600^{\circ}$ que o investimento público no sistema educativo é prioritário e será atendido com os recursos que determinem os orçamentos da Nação, das Províncias e do Governo da Cidade de Buenos Aires. Segundo a Lei, este investimento deve ser aplicado à razão de $20 \%$ anual a partir do orçamento de 1993, ou devia considerar-se um incremento de 50\% na porcentagem do PIB destinado à educação em 1992. Para implementar o cumprimento destas disposições, a lei estabelece que o Estado Nacional, as províncias e o Governo da cidade de Buenos Aires deviam formalizar um "Pacto Federativo Educativo"3.

3 O Pacto Federativo Educativo foi promulgado em 1994 e ratificado pela Lei $n^{\circ}$ 24.856/97, em cumprimento ao artigo 63 da Lei Federal de Educação; trata-se de um acordo entre províncias e Governo Nacional para que houvesse a garantia de recursos para o cumprimento desta lei. 
De acordo com este Pacto, o Ministério Nacional se comprometeu a investir \$3.000 milhões entre 1995 e 1999 em infra-estrutura, equipamento, e capacitação docente, enquanto as províncias deveriam contribuir com 20\% deste valor, quando as ações fossem colocadas em prática. No entanto, ao longo desse período o valor de $\$ 3.000$ nunca foi alcançado e o que se conseguiu neste sentido foi um investimento de $40 \%$ deste valor (CTERA, 2005). Veja a tabela abaixo, que traz o gasto educativo como porcentagem do gasto total e com relação ao PIB, a partir de 1993, para o total do país:

\section{Tabela 2 - Gasto educativo}

\begin{tabular}{|c|c|c|}
\hline Ano & $\begin{array}{c}\text { Gasto Educativo como } \\
\text { Porcentagem do Gasto } \\
\text { Total (\%) }\end{array}$ & $\begin{array}{c}\text { Gasto em } \\
\text { Educação com } \\
\text { relação ao PIB (\%) }\end{array}$ \\
\hline 1993 & 11,9 & 3,8 \\
\hline 1994 & 12,0 & 3,8 \\
\hline 1995 & 12,2 & 4,0 \\
\hline 1996 & 12,6 & 3,8 \\
\hline 1997 & 13,1 & 4,0 \\
\hline 1998 & 13,1 & 4,1 \\
\hline 1999 & 13,4 & 4,6 \\
\hline
\end{tabular}

Fonte: Cippec

A tabela acima mostra que a relação Gasto Educativo/PIB aumentou ao longo do período analisado, mas esta variação é resultado do baixo desempenho da economia e não de um aumento real do gasto no setor. A relação acima exemplificada (Gasto Educativo/PIB) é relevante porque demonstra a importância dada pelo Estado a uma determinada área, já que se está falando no quanto este Estado a inclui em seu orçamento. Assim, podemos inferir que os objetivos da Lei Federal de Educação de 1993 não têm sido alcançados tanto em termos de aumentar o gasto total a $20 \%$ anual, como aumentar a porcentagem do PIB destinado à educação para 6\%.

A educação é atendida principalmente pelo Estado e o investimento que este destina a este setor constitui um dos principais componentes do gasto público social, perdendo somente para o gasto com previdência social, conforme tabela abaixo:

\section{Tabela 3 - Gasto público Social}

\begin{tabular}{|c|c|c|c|c|c|c|c|c|c|}
\hline \multicolumn{10}{|c|}{ Gasto público Social Consolidado por função 1993-2000 - em \% } \\
\hline 芫 & 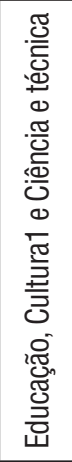 & 䎡 & 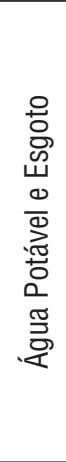 & 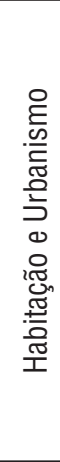 & 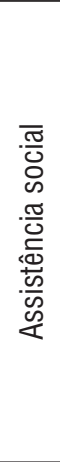 & 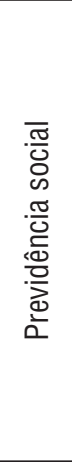 & 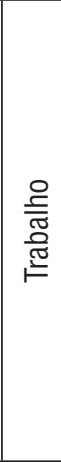 & 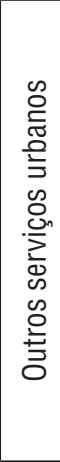 & 覀 \\
\hline 1993 & 20.17 & 22.80 & 0.88 & 2.29 & 5.54 & 38.95 & 4.17 & 5.20 & 100.00 \\
\hline 1994 & 19.70 & 23.31 & 0.77 & 2.31 & 5.56 & 39.29 & 4.33 & 4.73 & 100.00 \\
\hline 1995 & 20.27 & 23.41 & 0.97 & 2.02 & 4.97 & 39.56 & 4.54 & 4.26 & 100.00 \\
\hline 1996 & 20.68 & 22.91 & 0.74 & 2.11 & 4.77 & 39.88 & 4.53 & 4.39 & 100.00 \\
\hline 1997 & 21.77 & 22.81 & 0.87 & 2.35 & 5.68 & 37.86 & 4.35 & 4.31 & 100.00 \\
\hline 1998 & 22.10 & 22.87 & 0.77 & 2.47 & 5.76 & 37.28 & 4.28 & 4.46 & 100.00 \\
\hline 1999 & 22.95 & 23.48 & 0.65 & 2.05 & 5.68 & 36.55 & 4.15 & 4.48 & 100.00 \\
\hline 2000 & 23.34 & 23.02 & 0.47 & 1.80 & 5.37 & 37.34 & 2.10 & 4.46 & 100.00 \\
\hline
\end{tabular}

Fonte: Dados do Ministério da Economia e Finanças Públicas da República Argentina

\section{Fontes de Financiamento do Sistema educativo estatal}

O financiamento da educação é umas das principais preocupações quando se pensa em possibilidades de mudanças no sistema educativo. Isto porque a finidade de recursos é em si mesmo o grande nó-górdio para se implantar qualquer mudança no campo educacional por meio das políticas públicas.

Assim, segundo Morduchowicz, na Argentina o financiamento educativo está numa encruzilhada: se os recursos que se destinam ao setor são baixos, isto se deve a fatores estruturais como a escassa arrecadação impositiva que dificulta seu incremento.

A principal fonte de recursos para a educação são os impostos e, dada a estrutura federal da Argentina, se tratam de impostos arrecadados tanto em nível provincial como nacional. O sistema educativo da Argentina se sustém em sua maior parte com recursos de livre disponibilidade: são as chamadas "receitas gerais" que se distribuem livremente de acordo com critérios político-econômicos dos governantes, já explicados anteriormente (MORDUCHOWICZ, 2002). 
Os recursos próprios das províncias são compostos por recursos tributários, não-tributários e de capital, sendo que a participação destes dentro do total que as províncias arrecadam é em média 49,5\%; embora existam províncias que apresentam um grau de autofinanciamento que Ihes permite certa independência em relação aos recursos de origem nacional: Buenos Aires, Córdoba, Mendonza, Santa Fé e a cidade de Buenos Aires são exemplos destas.

\section{O sistema de co-participação federal de imposto}

A condição básica para o cumprimento do equilíbrio nas contas do setor público é que seus recursos sejam suficientes para cobrir todos os tipos de despesas. Na Argentina há diferentes tipos de transferências intergovernamentais, classificadas segundo seus destinos, as quais tiveram origem na dependência que as províncias têm em relação à Nação. Essas transferências podem ser:

1. Transferências condicionadas são aquelas em que o governo central decide quanto e onde as mesmas devem ser aplicadas;

2. Transferênciasnão-condicionadassãofundos de livre disponibilidade, alocadas de acordo com as prioridades e preferências do governo local. Estas ainda podem ser a) automáticas (quando há distribuição do produzido por determinado tributo nacional de acordo com porcentagens pré-estabelecidas) ou b) discricionárias (que se distribuem por critérios específicos - ad hoc) (CENTRANGOLO e JIMENEZ, 1995).

O regime de co-participação federal de impostos existente na Argentina, uma das formas mais conhecidas de transferências de recursos do governonacional paraasprovíncias, écaracterizado como um mecanismo de redistribuição nãocondicionado e automático; essas transferências automáticas sustentam parcialmente e de maneira indireta os serviços públicos que devem ser ofertados pelas províncias. No que se refere ao caso específico da educação, o sistema educativo argentino tem sua maior sustentação financeira dada por essas transferências não condicionadas, isto é, os fundos que chegam às províncias por meio deste mecanismo não estão condicionados a nenhum uso específico, podendo as autoridades locais decidir livremente onde empregá-los (MORDUCHOWICZ, 2002).

\section{Origens e funcionamento do sistema de co-participação federal de impostos}

O regime de co-participação federal de impostos é o mecanismo de transferência intergovernamental mais importante da Argentina e tem como um de seus principais objetivos alcançar uma maior uniformidade no fornecimento dos bens públicos no país. Teve origem em 1935 com a aprovação das leis 12.139, 12.143 e 12.147, que determinaram a expansão do volume de recursos arrecadados pela Nação; tem um fim redistributivo, já que se propõe a favorecer as províncias mais pobres e com menor capacidade produtiva através do reparto de recursos arrecadados a nível nacional. É fundamentado na centralização de receitas no âmbito federal e na distribuição da mesma para as províncias.

Na década de 1950 se configurou um regime de co-participação que se estendeu até 1973, que se caracterizava pela incorporação de novos impostos no total a distribuir e pela presença de três mecanismos diferentes de distribuição, os quais eram principalmente devolutivos (as províncias que mais contribuíam ao fundo de coparticipação também eram aquelas para as quais mais se transferiam os recursos do sistema) e com porcentagens estabelecidas de acordo com critérios explícitos.

A partir de 1973 o regime de co-participação passou a ser regulado pela lei 20.221, que apresentava basicamente quatro características

1. foi chamada a primeira lei integral de coparticipação federal, já que pela primeira vez se compreendia todos os impostos nacionais (excluindo-se aqueles sobre o comércio exterior e aqueles que tenham uma alocação específica, como os recursos da seguridade social) a distribuir-se entre a Nação e as províncias em um único regime;

2. se estipulou coeficiente igual para a Nação e as províncias na distribuição primária (entre Nação e total que seria destinado às províncias): 48,5\%, o mais alto desde a criação do sistema; 
3. criação de um Fundo de Desenvolvimento Regional ${ }^{4}$, financiado com os $3 \%$ restantes; e 4. os coeficientes de redistribuição secundária (entre províncias) estipulados pela lei eram resultantes da combinação de três critérios: $65 \%$ diretamente proporcional à população; $25 \%$ em relação à diferença de desenvolvimento entre as regiões e 10\% segundo a densidade de população.

A década de 1980 marcou uma nova etapa nas relações financeiras entre os governos nacional e provinciais, com maiores conflitos entre as duas esferas. Nesta época os planos de estabilização da economia implementados pelo governo geraram a necessidade de uma reforma tributária que objetivava reduzir os custos da produção substituindo-os por uma carga tributária sobre o consumo doméstico. Para isso, houve a eliminação das contribuições patronais ao sistema previsional e ao Fundo Nacional de Habitação (FONAVI), a qual seria compensada pelo incremento das alíquotas do imposto ao valor agregado (IVA) e ampliação de sua base.

No entanto, como o IVA fazia parte do volume de recursos que integrava o sistema de coparticipação, o governo precisou reformá-lo como um todo para que o imposto, de fato, substituísse o financiamento do sistema previsonal. A Lei 22.293 instituiu que o valor equivalente ao que era destinado pelas contribuições patronais ao FONAVI e ao sistema previsonal, seria deduzido dos recursos co-participáveis, medida que muito afetou a situação financeira das províncias. Importa citar também que entre 1977 e 1980, houve a transferência da educação primária, saúde, obras sanitárias e da Empresa Nacional de Água e Energia Elétrica às províncias, sem que houvesse uma correspondente transferência de recursos (Cetrangolo e Jimenez, 1995).

As consequências destas medidas foram sentidas nos anos posteriores, quando cerca de $45 \%$ dos recursos da co-participação eram destinados ao FONAVI e ao sistema previsional.

4 O Fundo de Desenvolvimento Regional foi criado com o objetivo de financiar investimentos em trabalhos públicos de interesse provincial ou regional, destinados à formação de infra-estrutura requerida para o desenvolvimento do país.
Para cobrir os déficits provinciais, foram usados os Aportes do Tesouro Nacional (ATN) ${ }^{5}$ para que as mesmas pudessem cobrir seus gastos.

Em 1984, a lei 20.221 expira e a falta de acordo em relação à distribuição secundária deixa um vazio legal nas relações financeiras entre as jurisdições; as transferências passam a ser substituídas pelos ATNs. Além disso, há uma modificação na relação entre Governo Nacional e províncias, já que mesmo tendo a maioria no Congresso Nacional, o Governo Nacional era minoria no Senado e tinha poucos governos nacionais como aliados (Cetrangolo e Jimenez, 1995). O Governo Nacional teve perdas de apoio popular e as negociações tenderam a favorecer as demandas provinciais.

Em 1988 foi sancionada a lei 23.548, que estabeleceu um regime transitório de distribuição de recursos fiscais entre a Nação e as províncias; foi chamada de "Regime Transitório de Coparticipação Federal", mas se encontra em vigor até hoje, já que disputas políticas entre as partes envolvidas impedem um avanço nas negociações sobre as mudanças no sistema. A partir desta lei o volume de impostos que seria coparticipado passou a ser integrada por todos os impostos nacionais existentes na data da norma ou a serem criados a partir dela. O volume a ser distribuído passou a obedecer as seguintes porcentagens: $42,34 \%$ à Nação; $54,66 \%$ ao conjunto das províncias; $2 \%$ para a recuperação do nível relativo das províncias de Buenos Aires, Chubut, Neuquén e Santa Cruz e 1\% para o Fundo de Aportes do Tesouro Nacional das províncias. É importante fazer referência de que essas porcentagens foram mudando ao longo do tempo, por causa de necessidades de ordem conjuntural das províncias, do poder de determinados governantes ou por causa de outros critérios que não obedeceram nenhuma lógica que pudesse ser inteligível de maneira clara.

A distribuição secundária das transferências, entre províncias, depende de uma série de parâmetros que variam de acordo ao tipo de transferência que se considere. No caso do sistema de coparticipação, os fundos se repartem de acordo

\footnotetext{
5 Criado para atender as situações de emergência e os desequilíbrios financeiros dos governos provinciais. Fonte: Lei 24.548/88.
} 
com as porcentagens estabelecidas em lei, as quais não obedecem nenhum critério explícito, como os critérios que regiam a lei anterior (Lei 20.221). A lei 23.548 tem seus parâmetros de redistribuição baseados na redistribuição realizada entre os anos de 1984-1987, período em que não existia uma norma para reger a coparticipação, quando a redistribuição passou a ser feita por meio de acordos bilaterais com os governadores, ou seja, dependia mais da necessidade e do poder de negociação de cada província. A Constituição Nacional argentina de 1994 não deixa claro os critérios que deverão ser seguidos para essa distribuição secundária; em seu artigo 75, inciso 2, está escrito que "a distribuição entre a Nação, as províncias e a cidade de Buenos Aires e entre estas, se efetuará em relação direta às competências, serviços e funções de cada uma delas, contemplando critérios objetivos de distribuição; será equitativa, solidária e dará prioridade ao alcance de um grau equivalente de desenvolvimento, qualidade de vida e igualdade de oportunidade em todo o território nacional." Em outras palavras, não há o estabelecimento de regras explícitas que tenham que ser seguidas na redistribuição dos recursos coparticipáveis, o que facilita práticas clientelistas na negociação dos mesmos.

Entre os principais problemas deste sistema, podemos citar 1) a complexidade e discricionalidade na coparticipação primária, 2) oscilações nos valores transferidos, que se relacionam com a situação econômica do país, uma vez que a massa coparticipável é composta por elementos muito relacionados com o ciclo econômico do país 3) baixos incentivos para a solvência fiscal e 4) complexidade do sistema (MEZZADRA e RIVAS, 2005). Para as províncias que tem menor potencial de arrecadação de impostos, por exemplo, o regime de concentração e posterior redistribuição dos mesmos as beneficiam; as províncias maiores acabam perdendo duplamente: pela dependência e pelas perdas que supõe a redistribuição (MORDUCHOWICZ, 2002, p.40). Regiões como Terra do Fogo, Santa Cruz e Neuquén, que possuem maior potencial de arrecadação (mais de $\$ 900$ anuais por habitante), recebem menos dos impostos coparticipados quando comparadas com as províncias com menor potencial de arrecadação, como é o caso de Formosa, Corrientes, Santiago de Estero e Chaco. Essas últimas, apesar de arrecadarem menos (cerca de $\$ 150$ anuais por habitante), acabam recebendo mais da massa co-participada.

À primeira vista essa situação se apresenta como justa, pois se estamos falando de um sistema que busca corrigir distorções entre as províncias, parece lógico que aquelas que arrecadam menos (ou seja, as províncias mais pobres) sejam as províncias que devam receber mais da coparticipação. No entanto, em um olhar mais atento aos números, levando-se em conta as províncias acima citadas, percebe-se que a realidade é um pouco diferente. Quando combinamos algumas variáveis, como a porcentagem de Necessidades Básicas Insatisfeitas, o potencial de arrecadação por habitante e a quantidade de dinheiro recebida por essas províncias via co-participação, temos a seguinte situação:

\section{Quadro 1. Perfil das províncias: população, recursos recebidos e valores per capita}

\begin{tabular}{|c|c|c|c|c|c|}
\hline 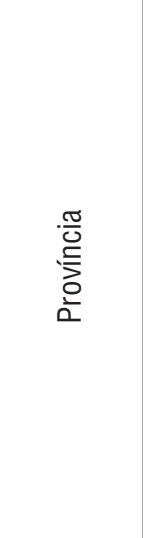 & 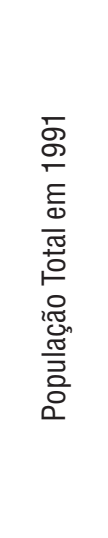 & 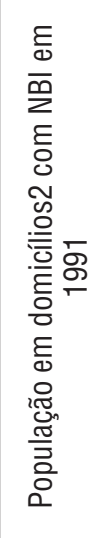 & 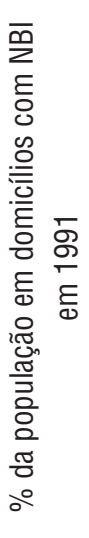 & 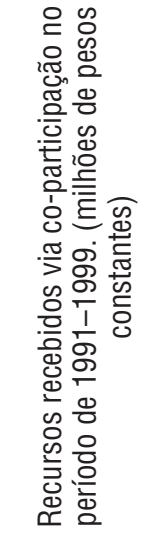 & 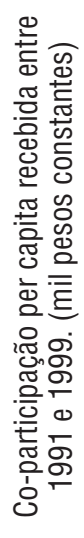 \\
\hline Chaco & 834.128 & 329.139 & 39,5 & $9.666 .477,30$ & 11,58 \\
\hline Corrientes & 790.786 & 248.144 & 31,4 & 7.552.956,12 & 9,55 \\
\hline Formosa & 396.428 & 155.072 & 39,1 & $7.200 .019,84$ & 18,16 \\
\hline Neuquén & 380.300 & 81.391 & 21,4 & $3.432 .706,44$ & 9,02 \\
\hline $\begin{array}{c}\text { Santa } \\
\text { Cruz }\end{array}$ & 155.791 & 22.860 & 14,7 & 3.127.945,04 & 20,07 \\
\hline $\begin{array}{c}\text { Santiago } \\
\text { del Estero }\end{array}$ & 666.857 & 254.830 & 38,2 & 8.171.447,92 & 12,25 \\
\hline $\begin{array}{c}\text { Tierra del } \\
\text { Fuego }\end{array}$ & 66.314 & 14.862 & 22,4 & $1.350 .495,84$ & 20,36 \\
\hline
\end{tabular}

Fonte: Elaboração própria com base nos dados do Censo 1991 e em dados do Ministério de Economia e Finanças públicas. 
Ao obtermos os valores per capita de recebimento via coparticipação pelas províncias, temos que uma província com $39,5 \%$ de sua população em domicílios com $\mathrm{NBI}$, Chaco, recebe muito menos do que a população de Terra do Fogo, que tem 22,4\% da população sob as mesmas condições. Quando se fala de números absolutos, percebe-se que no Chaco há 329.139 pessoas em domicílios com NBI, enquanto na Terra do Fogo esse número cai para 14.862 .

Nota-se então que, embora as províncias possuam impostos próprios, a arrecadação dos mesmos é muito desigual e está fortemente atrelada ao desenvolvimento econômico de cada região. Diante dessas constatações, o questionamento que se coloca é o seguinte: porque uma população tão pequena (em comparação com a do Chaco) como a da Terra do Fogo, recebe quase o dobro da massa co-participada quando se considera o valor por habitante?

Outro dado que chama a atenção no quadro acima é o de Formosa, que tem 39,1\% (155.072 pessoas) de sua população em domicílios com NBI e recebeu do sistema de co-participação, entre 1991 e 1999, um valor per capita de 18,16 mil pesos e Santiago de Estero, com 38,2\% da população (254.830 pessoas) com NBI e recebeu 12,25 mil pesos do mesmo sistema no período analisado.

Ora, uma vez que se trata de um sistema que busca certa equidade entre as províncias, essa situação não deveria existir. Tal situação evidencia as contradições do sistema de co-participação apontadas por vários autores (Porto e Sanguinetti 1996, Morduchowich 2002, Mezzadra e Rivas 2005, entre outros).

A figura do mapa abaixo mostra a situação das províncias de acordo com o índice de desenvolvimento humano ${ }^{6}$ e nos auxiliará a corroborar a ideia acima:

60 Índice de Desenvolvimento Humano (IDH) foi criado por Mahbub ul Haq, com a colaboração do economista indiano Amartya Sen, e leva em consideração o PIB per capita, a longevidade e a educação e busca, por meio da análise dessas variáveis, medir o avanço de uma população. A avaliação da educação é feita pelo índice de analfabetismo e taxa de matrículas em todos os níveis de ensino. Fonte: <http://www.pnud.org.br/idh>.

\section{Figura 1. Províncias conforme IDH}

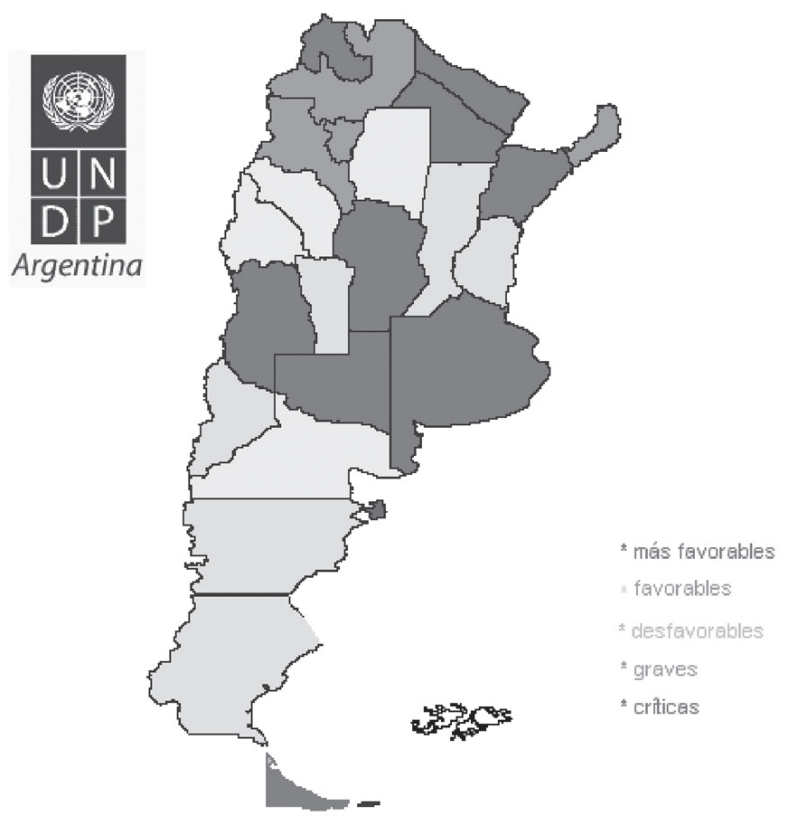

As regiões em vermelho, consideradas "críticas", correspondem às províncias de Jujuy, Formosa, Chaco e Corrientes; as hachuradas em laranja, consideradas em situação "grave", são Salta, Tucumán, Catamarca, e Misiones. Rio Negro, San Juan, La Rioja e Santiago de Estero são classificadas como províncias em situação desfavorável. O restante das províncias está hachurado em azul e se encontra em situação "favorável" ou "mais favorável". São elas: Terra do Fogo, Santa Cruz, Chubut, Neuquén, San Luis, Santa Fé, Entre Rios, Buenos Aires, La Pampa, Mendoza e Córdoba.

Ao considerarmos as províncias analisadas no quadro anterior, vemos que Chaco, Corrientes, Formosa e Santiago de Estero se acham em situação crítica ou desfavorável, enquanto Neuquén, Santa Cruz e Terra do Fogo estão em posição bem mais favorável, mas receberam valores per capita muito diferentes do sistema de co-participação, principalmente quando comparamos as duas primeiras: Santa Cruz que tinha 22.860 pessoas vivendo em domicílios com $\mathrm{NBI}$ recebeu bem mais do sistema de co-participação que Neuquén, que tinha 81.391 pessoas nesta situação. Isso indica que, realmente, o sistema de co-participação não ameniza as desigualdades existentes entre as províncias. 


\section{O sistema de co-participação e a educação na Argentina}

A questão federal do financiamento educativo na Argentina se caracteriza pela necessidade de uma forte redistribuição de recursos na tentativa de garantir uma convergência nos indicadores de capital humano e renda entre as províncias argentinas. Neste contexto, a relação financeira existente entre os distintos níveis de governo se coloca como uma questão central, uma vez que há uma relação de interdependência entre os entes federados. Embora $40 \%$ do gasto público estejam descentralizados entre as províncias, é o Governo Nacional que possui a maior capacidade de arrecadação dos impostos que financiam estes serviços (80\%), o que exemplifica esta forte dependência entre Governo Nacional e províncias.

As diferenças na quantidade total de recursos que cada província tem refletem diretamente na distribuição do gasto educativo, como fica evidenciado na situação de Terra de Fogo e Corrientes que gastam, por ano, na educação pública uma média de $\$ 2.500$ e $\$ 800$, respectivamente, por aluno (Mezzadra e Rivas, 2005). O sistema de coparticipação é o principal fator explicativo dessas grandes diferenças existentes entre as províncias no financiamento da educação, já que o gasto por aluno está relacionado com os recursos das províncias e não necessariamente com seu desenvolvimento econômico.

Já quando falamos na porcentagem do gasto educativo dentro do gasto público total das províncias, temos outra situação: províncias que tem um gasto por aluno considerado alto, ou seja, províncias que tem maiores recursos, como Terra do Fogo não necessariamente destinam grande parte de seus gastos públicos à educação. Isso ocorre porque, além da questão financeira que envolve esse processo, as províncias possuem um espaço de ação em que seus governantes podem decidir o quanto vão destinar à educação. Por isso, conforme o governo em questão, o gasto educativo pode ter grandes variações, aumentando ou diminuindo de acordo com a prioridade que eles dão a essa área. Por isso, também não é possível afirmar de forma enfática que as províncias mais pobres são aquelas que menos investem em educação; não se trata de uma questão unicamente financeira, mas também de negociações e vontade política.

\section{Referências Bibliográficas}

CETRANGOLO, 0. D., JIMENEZ, J. P., EL conflicto em torno a las relaciones financieras ente la Nación y las provincias. Primera Parte: Antecedentes de la LEY 23.548. Setembro de 1995. Disponível em: www.cece.org.ar/fse09. Acesso em Janeiro/2010

FALLETI, Tulia G. Descentralización educativa en Argentina. Condicionantes institucionales y consecuencias políticas. In A. Clemente and C. Smulovitz (eds.) Descentralización, políticas sociales y participación democrática en Argentina, Buenos Aires: IIED-AL, 2004, 93-122. Disponível em: http://www.catedras.fsoc.uba.ar/udishal/elatina/08jul-set2004.pdf.

KRAWCZYK, Nora Rut. Aportes para pensar e resignificar la descentralización docente. In: Transformaciones en los procesos de geston educacional en el marco de la descentralizacion: estudio de cuatro paises (Argentina, Brasil, Chile e Colômbia). EL caso argentino. Flacso, 2005.

MEZZADRA, F. e RIVAS, A. Coparticipación y equidad educativa: un debate pendiente en el campo de la educación, Serie de Estudios sobre el poder y la educación en la Argentina, Documento de Análisis de Políticas Públicas № 8, CIPPEC, Buenos Aires, 2005.

MORDUCHOWICZ, Alejandro. El financiamineto educativo en Argentina: problemas estructurales, soluciones coyunturales. Unesco. 2002.

NICOLINI, J.P., SANGUINETTI, P., SANGUINETTI, J. Análisis de alternativas de financiamiento de la educación básica argentina em el marco de las instituciones fiscales. 2001. Disponível em: http://www.iadb.org/intal/aplicaciones/uploads/ponencias/Foro_ INTAL_2001_04_trabajo14.pdf. Acesso em Abril de 2010.

RIVAS, Axel, VELEDA, Cecília e outros. Los Estados provinciales frente a las brechas socio-educativas: uma sociologia política de las desigualdades educativas en las provincias argentinas. 2004. Disponível em: http://cippec.com/nexos/documentos/informe_final_ cippec.pdf. Acesso em 1/11/2009. 


\section{Anexo:}

Publicado por ARGENPRESS en 16:22:00

miércoles 23 de diciembre de 2009

Argentina: Coparticipación federal. ¿Dónde está el federalismo?

Arturo M. Lozza (ACTA)

Sólo poco más del 30\% de lo que se recauda nacionalmente llega a las provincias a través de la coparticipación, pero en esta distribución injusta de los ingresos deciden todavía las concepciones neoliberales donde los que más tienen son los que menos pagan impuestos. La paradoja de una Nación superavitaria con provincias endeudadas y sus cuentas en rojo.

Desde la Constitución de 1853 Argentina adoptó el sistema federal de gobierno, por lo cual los poderes institucionales se establecen en tres niveles: Nacional, Provincial y Municipal. Se distribuyen así las funciones gubernamentales y administrativas, pero también lo que se recauda en materia de impuestos. Esa distribución desde la Nación a las Provincias, y de éstas a los municipios, se realiza desde 1935 a través, principalmente, de lo que se denomina ahora coparticipación federal de los impuestos nacionales. Lo que corresponde a cada segmento se fue estableciendo en las últimas décadas mediante pactos fiscales entre la Nación y las provincias.

Ahora bien, la Constitución Nacional en su articulo 75 establece no sólo que las provincias deben tener aseguradas automáticamente las remesas de los montos correspondientes, sino que advierte que ésta distribución deberá ser equitativa, solidaria y procurar la "igualdad de oportunidades en todo el territorio nacional". Y ahí está la madre del borrego. Las cláusulas constitucionales jamás llegaron a cumplirse, sencillamente porque todo lo que significa impuestos, lo que es coparticipación y lo estrechamente vinculado a la distribución de ingresos, es cuestión política a la enésima potencia, es cuestión de lucha de clases, es supervivencia o no de un sistema, es relación de fuerzas. Y los que tienen la sartén por el mango no son precisamente los trabajadores sino el gran capital.

Veamos, si no, la historia argentina. La apropiación de las rentas fiscales ha sido motivo esencial de disputas y guerras internas en las épocas de enfrentamientos entre federales y unitarios. Jamás la oligarquía y los intereses financieros foráneos han dejado de cinchar en esta pugna, aún en nuestros días. Cada pacto fiscal ha sido una pelea por la apropiación de beneficios. Porque detrás de ellos, entre bambalinas, se han movido transas políticas, complicidades entre los poderes políticos y el capital concentrado, luchas feroces para anular o aplicar impuestos a favor o en contra de determinado segmento y, especialmente en las décadas recientes, por la influencia decisiva del poderoso sector financiero internacional con sus cláusulas sobre deuda externa que han determinado que en épocas de la dictadura genocida y en la del menemato, el pago de los compromisos con la banca vinculada al FMI, BID y Banco Mundial recayeran sobre las provincias que han visto así disminuir drásticamente sus ingresos por coparticipación. De esta manera, el federalismo no ha sido más que una ficción.

\section{Pan para hoy, hambre para mañana}

Hoy se habla una vez más de concretar otro pacto fiscal para encontrar fórmulas de una mejor distribución de ingresos coparticipados. Esta esperanza, sin embargo, se hace más distante si partimos del hecho que nuevamente desde el Estado nacional se pretende volver al círculo perverso del FMI que permita "platita dulce" para hoy, pero más hambre para mañana. Es historia conocida.

Pero hagamos algunas referencias comparativas. Durante el trienio de la administración justicialista de la Nación (1973/75) se incrementó la coparticipación automática a favor de las provincias, alcanzando durante 1975 al 52,4 por ciento de la recaudación total de impuestos nacionales.

Pero con Martínez de Hoz, en los años de la dictadura genocida instalada en 1976, comenzó a reducirse 
fuertemente esta participación provincial ubicándose hoy en alrededor del 30\%. De todas maneras, a través de otros mecanismos distintos a los de la coparticipación, el Ejecutivo nacional ha ido trasfiriendo fondos, no sujetos a reglas preestablecidas, los cuales no hacen variar los conceptos de fondo.

Tal situación provocó que el Estado Nacional se haya convertido en el principal acreedor de una creciente deuda de las provincias, estimada en alrededor de 80.000 millones de pesos.

Evidentemente, una de las provincias más perjudicadas por esta concentración de la recaudación es la de Buenos Aires que hoy aloja en el conurbano a más de 10 millones de habitantes con dramáticos cuadros de miseria y marginación social, alberga casi el 40 por ciento de la población y de la pobreza total del país, registra elevados índices de carencia de servicios básicos como agua potable y cloacas; además aporta más del 35\% del PBI nacional. Sin embargo, apenas recibe el 21\% de los menguados fondos coparticipados.

En fin, cada provincia puede mostrar también cuotas de injusticia distributiva. Sin embargo, caeríamos en facilismos o falsas conclusiones si dijéramos que la lucha es simplemente entre Nación y Provincias. Esa pugna existe, pero la mayoría de las veces está mitigada por coincidencias de ambas partes en definiciones neoliberales. En cambio, en los resultados de esos "pactos fiscales" se refleja de un modo u otro la pelea verdadera, la de fondo, que es entre el interés del pueblo trabajador, por un lado, y los del capital concentrado, la oligarquía y los intereses financieros, por el otro. Y son estos últimos los que van ganando en la porfía.

Es decir, el combate por quien se queda con la mejor porción de la torta, se da asimismo en la distribución de la coparticipación y, sobre todo, en la recaudación impositiva, en qué se distribuye y en cómo se concreta.

Si existen exenciones impositivas para las millonarias transacciones financieras (porque sigue vigente la Ley de Entidades Financieras de la dictadura), si no se aplican las retenciones que corresponden a los grandes grupos sojeros (de la producción y de la exportación), si no se pone freno a la evasión de ganancias a los paraísos fiscales, si se mantienen los privilegios a las multinacionales del petróleo y la minería, y, en cambio, la principal fuente de recaudación de impuestos proviene del consumo del pueblo a través del IVA, siempre la coparticipación federal se asentará sobre cimientos de injusticia. Porque lo que se coparticipará será la consecuencia de una política regresiva en materia de impuestos.

Un estudio realizado por la Asociación Trabajadores del Estado (ATE-CTA) bonaerense acerca del Presupuesto 2010 sostiene que la coparticipación no puede realizarse equitativamente sin existir políticas fiscales activas y un sistema impositivo progresivo orientado a una mayor presión recaudatoria sobre quienes más tienen, aquellos sectores que concentran la riqueza en nuestra "Provincia rica", que se distribuye tan injustamente.

Los trabajadores no somos los responsables, sino las víctimas, de esa regresión. Por eso no aceptamos que se utilice como excusa para que se congelen los salarios del sector estatal el argumento de que no existen fondos por la caída de la coparticipación.

Los trabajadores no aceptamos ser la variable de ajuste en esta crisis de las cuentas públicas. Una y mil veces nuestra Central ha señalado, sin respuestas desde el Gobierno, de dónde podrían salir los fondos para financiar una justicia distributiva. $Y$ señalamos que las provincias, sobre la base de una reforma a fondo de las políticas impositivas, tienen el derecho a recibir una justa porción de la recaudación nacional. Porque el dinero está, y habrá que extraerlo de quienes lo concentran en beneficio propio y en detrimento del interés nacional. 